\title{
Changes in arboreal ant populations following pruning of coffee shade-trees in Chiapas, Mexico
}

\author{
Stacy M. Philpott \\ Department of Ecology and Evolutionary Biology, University of Michigan, Ann Arbor, MI 48109, USA; \\ Current address: Smithsonian Migratory Bird Center, National Zoological Park, 3001 Connecticut Ave. NW, \\ Washington, DC 20008, USA; (e-mail: sphilpot@umich.edu; phone: +202-673-0128; fax: + 202-673-4916)
}

Received 13 August 2003; accepted in revised form 22 August 2004

Key words: Azteca, biological control, Camponotus, Chiapas, Management system, Mexico

\begin{abstract}
Reducing or eliminating shade cover in coffee (Coffea arabica L.) agroforestry systems affects fungal disease and pest outbreaks, coffee yields, and can result in biodiversity loss of important predators, such as ants. Less dramatic changes in shade structure or composition may also affect ants. Shade tree pruning, a common management practice in shaded coffee systems, has unknown consequences for ant communities. The effects of pruning on arboreal ant communities were investigated by measuring ant abundance, distribution, and species richness in the short (1 week) and long-term (6 months) after shade tree pruning in one $25 \times 50 \mathrm{~m}$ plot. Shade tree pruning significantly affected the distribution and abundance of two of the most common ant species (Azteca instabilis F. Smith and Camponotus senex textor Forel), and in general did not affect other ants. After pruning, $C$. senex textor ants were $80 \%$ more abundant on coffee plants and shade trees, whereas $A$. instabilis abundance dropped by $40 \%$ on coffee plants and $73 \%$ on shade trees after pruning. Additionally, $C$. senex textor were significantly more widespread, whereas $A$. instabilis distributions were more restricted. The effects of pruning were strong over the short-term, but were not evident over the long-term. Shade tree pruning did not affect ant diversity. Thus shade tree pruning largely affected certain aspects of arboreal ant communities in one coffee agroforestry system, with important implications for biological control.
\end{abstract}

\section{Introduction}

Coffee (Coffea arabica L.) was traditionally cultivated under diverse shade canopies but recent, more intensive production is characterized by few or no shade trees and agrochemical use (Moguel and Toledo 1999). Farmers eliminate shade trees perceiving that sun-grown coffee will have higher yields (Beer et al. 1997) but coffee yields may be highest when grown under 25-50\% shade cover (Soto-Pinto et al. 2000). Although high shade cover levels may reduce yields, increased shade tree diversity has not been shown to negatively affect coffee yields (Romero-Alvarado et al. 2002; Peeters et al. 2003) and may offer advantages including product diversification, suppression of weed growth, improved soil fertility, and protection from insect pests (Beer et al. 1997).

Increased crop protection from insect pests in highly shaded, diverse coffee systems may result from high diversity and abundance of natural enemies such as ants therein (Perfecto et al. 1996). 
Ants are often used as biological control agents in agroforests (Way and Khoo 1992). In coffee systems, ants control coffee berry borers (Hypothenemus hampei Ferrari) (Velez et al. 2001) and may limit other pests (Vandermeer et al. 2002). Yet with coffee intensification, ant richness declines (Perfecto and Snelling 1995; Perfecto et al. 1997; Armbrecht and Perfecto 2003). Most attribute diversity losses to elimination or large modifications of shade tree number or richness, but smaller-scale changes such as shade tree pruning may also influence ant diversity. Shade tree pruning is advocated to control fungal pathogens, increase coffee yield, or for pest management strategies (Beer et al. 1997; Staver et al. 2001). Shade tree pruning also may affect arboreal ants, but little is known about the fate of arboreal ants whose nests fall during branch pruning, or if pruning may change ant distributions. If pruning significantly affects ant communities, pruning may also alter ants' function as biological control agents.

Here, the effects of how shade tree pruning, one important coffee shade management strategy, affects abundance, distribution, and diversity of ants in shaded coffee plantations were investigated; specifically: (1) Do abundances of particular ant species change after pruning? (2) Do the distributions of particular ant species change after pruning? (3) Does pruning influence the diversity of ants in coffee plants and shade trees? (4) Are the effects of pruning long-lasting? Furthermore, how pruning may influence use of ants as biological control agents in coffee systems is discussed.

\section{Methods}

In January 2000 , eight plots $(25 \times 50 \mathrm{~m})$ were established along a gradient of coffee intensification to monitor abundance, distribution, and diversity of arboreal ants under different coffee management. Every 6 months thereafter until June 2002, ants were surveyed in each plot. Shortly after the surveying one of the eight plots (17 January 2002), farm workers pruned all shade trees in the plot (including Alchornea latifolia Sw., Inga micheliana Harms, Inga rodrigueziana Pittier, Sanchezia sp., Schizolobium parahyba (Vell.) S.F. Blake, Virola guatemalensis (Hemsl.) Warb., and five unidentified trees). As part of the pruning strategy, farm workers also applied lime to trees with Azteca instabilis
F. Smith, an aggressive ant species, so that workers would not be bitten by ants. Thus all effects of pruning on the arboreal ant community include application of lime. Two days after workers finished pruning the area (1 February 2002), ants in the plot were resurveyed to assess the direct effects of pruning on arboreal ant communities. Although other plots were surveyed at the same time, no other plots were pruned. The pruned plot was located in Finca Irlanda $\left(15^{\circ} 11^{\prime} \mathrm{N}, 92^{\circ} 20^{\prime} \mathrm{W}\right)$ an organic, shaded coffee farm in the Soconusco region of Chiapas, Mexico, $40 \mathrm{~km} \mathrm{NE}$ of Tapachula, at $1000 \mathrm{~m}$ elevation.

In each plot, coffee plant and shade tree locations were mapped and ant abundance, distribution, species richness, and shade cover were surveyed seven times; five times before and twice after pruning. On shade trees, ants were sampled with tuna baits $(10 \mathrm{~g})$ checked after 30-45 min. On coffee plants, ants were sampled by shaking and kicking plants, and examining coffee plants for 2 min following disturbance. All ants were identified to morphospecies and were separated into five categories: (1) A. instabilis, (2) Camponotus senex textor Forel, (3) Crematogaster spp., (4) other ants, and (5) no ants. Ant abundance was calculated as the total number of plants in each ant category divided by the total number of coffee plants or shade trees. One sample $t$-tests were used to determine differences between proportions of coffee plants or shade trees in a particular category before and after pruning. Ant proportions under non-pruned conditions were compared to the pruned sample by using the pruned sample as the test value. All proportions were arcsine transformed. Mann-Whitney $U$-tests were used to calculate the probability of encountering a reversal in the proportions of particular pairs of ants.

The short- and long-term changes in distributions of common ants within the plot was assessed directly before (January 2002), after (February 2002), and long after (June 2002) pruning. To measure ant distributions within the plot, the $25 \times 50 \mathrm{~m}$ plot was divided into $5 \times 5 \mathrm{~m}$ quadrats and the number quadrats with a particular ant on either on coffee plants or shade trees were counted. Total numbers of occupied quadrats were compared to mean values using a $c h i^{2}$ test to compare values directly before and after or before and long after pruning. 
For each sampling date, species richness was recorded as the total number of morphospecies observed during any given sampling period. To assess differences between sampling dates and primarily between the non-pruned dates with the pruned date, EstimateS, which generates species accumulation curves from randomized data and also computes several species richness estimators, was used (Colwell and Coddington 1994; available at http://www/viceroy/eeb/uconn/.edu/estimates). Here, results for the Incidence-Based Coverage Estimator (ICE) and Chao2, both of which account for observed richness and number of uniques (number of species captured in only one sample) in making species richness estimations, are reported. These two estimators were used because ants are social insects making estimators based on numbers of singletons (number of species where only one individual was found) inappropriate Longino et al. 2002).

Percent shade cover in the plot was also surveyed. A grid of 50 total sampling points, each separated by approximately $5 \mathrm{~m}$, was established. At each point, presence or absence of foliage was surveyed using a densitometer and approximate shade cover was calculated by multiplying total points with shade by two. Differences in shade cover between the non-pruned and pruned sample dates were determined with one-sample $t$-tests.

\section{Results}

Shade tree pruning caused a large reduction in the percent shade cover in plots. For all other sampling dates (either before or 6 months after pruning), shade cover was significantly higher ( $>90 \%$ cover) than immediately after pruning ( $70 \%$ cover) (Table 1$)$.

Shade tree pruning also caused a dramatic change in the ant community, measured as changes in the abundance of two of the most common ants in the plot (Figure 1). Overall, the most commonly encountered ants were Crematogaster spp. (28\% of encounters on coffee trees and shade trees), Azteca instabilis (20\%) and Camponotus senex textor $(11.5 \%)$. Immediately after pruning, $C$. senex textor was found on $80 \%$ more coffee plants $(t=-11.50, p<0.001)$ and $85 \%$ more shade trees $(t=-9.146, p<0.001)$ than on nonpruned dates. In contrast, $A$. instabilis was found in $73 \%$ fewer shade trees $(t=8.634, p<0.001)$ and $36 \%$ fewer coffee plants $(t=6.705, p<0.001)$ after shade tree pruning. Abundances of Crematogaster spp. did not change with pruning (Table 1), nor did abundance of other ants (such as Pseudomyrmex spp., Nesomyrmex spp., or Pheidole spp.) change on coffee plants, but abundance of ants in the 'other ants' category was significantly lower on shade trees following pruning (Table 1). The effects of pruning on ant abundances did not persist, and by 6 months after pruning, ant abundances had returned to prepruning levels. Only immediately after pruning was $C$. senex textor more abundant on coffee plants than $A$. instabilis (Mann-Whitney $U$, $Z=-2.236, p=0.026$ ).

The spatial distributions of $C$. senex textor and $A$. instabilis immediately before and immediately after pruning were also significantly different (Figure 2). Before pruning (January 2002) A. instabilis was found on either coffee plants or shade

Table 1. Proportion of coffee plants and shade trees with Crematogaster spp., other ants, or without ants, and percent shade cover for six samples of one plot in Chiapas, Mexico where shade trees were not pruned, and for one sample where shade trees were pruned 1 week before sampling.

\begin{tabular}{|c|c|c|c|c|c|c|c|c|c|c|}
\hline \multirow[t]{2}{*}{ Plant } & \multirow[t]{2}{*}{ Ant category } & \multicolumn{6}{|c|}{ Not-pruned } & \multirow{2}{*}{$\frac{\text { Pruned }}{\text { Feb-02 }}$} & \multicolumn{2}{|c|}{$t$-Test results ${ }^{\mathrm{a}}$} \\
\hline & & Jan- 00 & Jan-01 & Jun-01 & May-01 & Jan-02 & Jun-02 & & $T$-statistic & $p$-value \\
\hline \multirow[t]{3}{*}{ Coffee } & Crematogaster spp. & 0.141 & 0.208 & 0.191 & 0.092 & 0.169 & 0.181 & 0.187 & -1.338 & 0.239 \\
\hline & Other ants & 0.132 & 0.09 & 0.211 & 0.138 & 0.294 & 0.235 & 0.197 & -0.622 & 0.561 \\
\hline & No ants & 0.595 & 0.561 & 0.347 & 0.6 & 0.333 & 0.416 & 0.259 & 4.537 & $0.006^{*}$ \\
\hline \multirow[t]{3}{*}{ Shade trees } & Crematogaster spp. & 0.286 & 0.351 & 0.286 & 0.121 & 0.097 & 0.176 & 0.176 & 0.81 & 0.455 \\
\hline & Other ants & 0.143 & 0.189 & 0.229 & 0.333 & 0.129 & 0.412 & 0.088 & 3.915 & $0.011 *$ \\
\hline & No ants & 0.286 & 0.216 & 0.229 & 0.364 & 0.323 & 0.059 & 0.265 & -0.596 & 0.577 \\
\hline$\%$ shade & & NA & 92 & 96 & NA & 100 & 90 & 70 & 11.049 & $0.002 *$ \\
\hline
\end{tabular}

${ }^{\mathrm{a}} T$-statistics and $p$-values are for one-sample $t$-tests comparing pruned with not-pruned samples. 
(a)

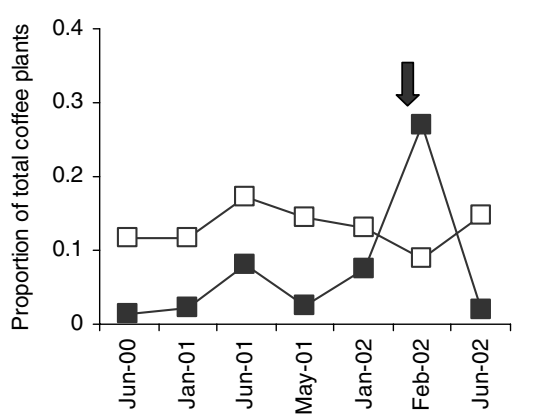

(b) $\rightarrow$ - Azteca instabilis

$\rightarrow-$ Camponotus senex textor

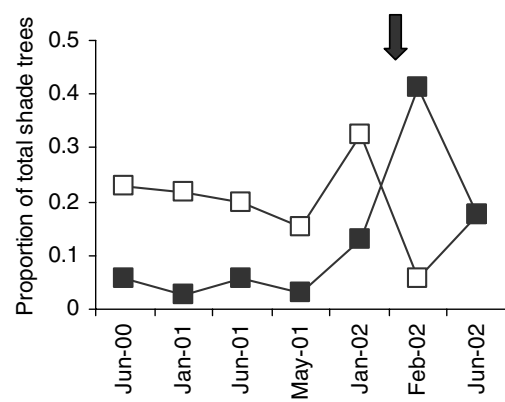

Figure 1. Proportion of coffee plants (a) and shade trees (b) with two ant species in a shaded-coffee farm plot in Chiapas, Mexico sampled over a 2-year period during which shade trees were sampled after sampling in January 2002 (indicated by arrows).
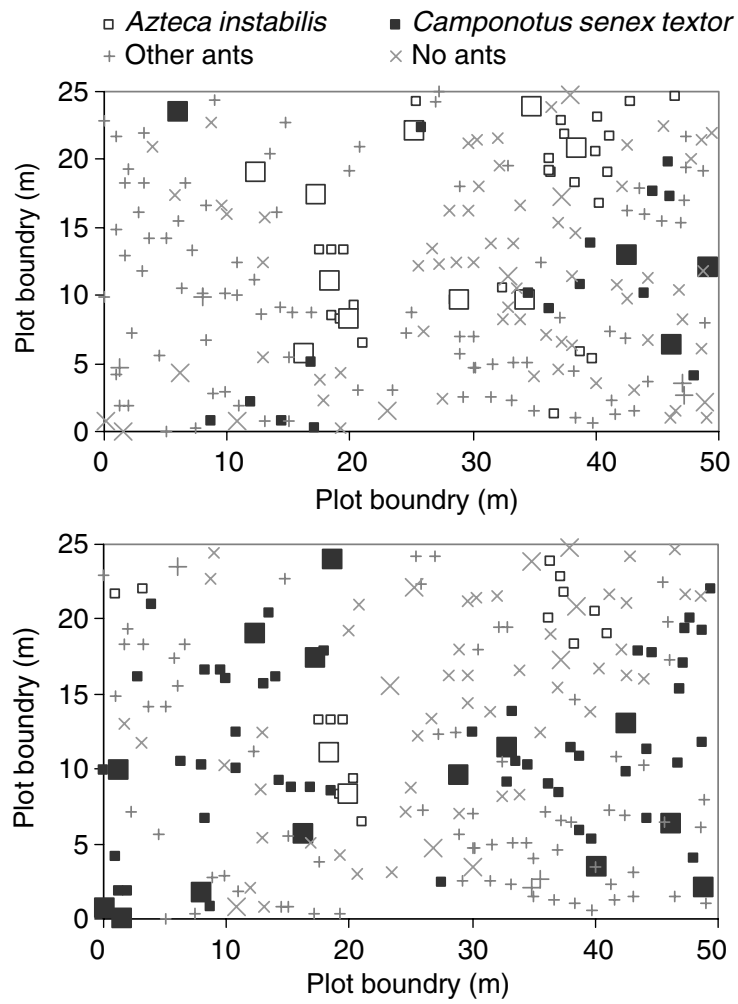

Figure 2. Arboreal ant distributions on coffee plants and shade trees in one $25 \times 50 \mathrm{~m}$ coffee farm plot in Chiapas, Mexico immediately before (a) and after (b) shade tree pruning. Small symbols show coffee plant locations within the plot and their ant occupants and large symbols show shade tree locations and their ant occupants. 'Other ants' represent all ants other than A. instabilis and C. senex textor that were encountered. trees in nearly half (12 of 25 ) of the $5 \times 5 \mathrm{~m}$ quadrats, but after pruning (February 2002) was only encountered in 7 of 25 quadrats. Camponotus senex textor was found in nearly twice as many quadrats (20 of 25) after pruning than before pruning (11 of 25). The relative change in numbers of quadrats occupied by $A$. instabilis and $C$. senex textor was significantly different $\left(\chi^{2}: p=0.047\right)$. However, the effects of pruning on ant distributions were not long-lasting. There were no significant differences in number of quadrats before (January 2002) and long after pruning (June 2002) with $A$. instabilis (12 vs. 9) or C. senex textor (11 vs. 5) $\left(\chi^{2}: p=0.101\right)$.

Ant diversity, in contrast, was not affected by pruning (Figure 3). Species accumulation curves for both observed and estimated richness were close to reaching asymptotes, thus one-way $t$-tests were used to compare richness in non-pruned dates to the pruned date. There were no significant differences between the pruned and non-pruned dates for observed richness $\left(S_{\mathrm{p}}=18, S_{\mathrm{np}}=14\right.$, $t=1.907, p=0.115)$, nor for ICE $\left(S_{\mathrm{p}}=22.8\right.$, $\left.S_{\mathrm{np}}=16.3, \quad t=1.972, \quad p=0.106\right)$ or Chao2 $\left(S_{\mathrm{p}}=29.9, \quad S_{\mathrm{np}}=16.8, t=1.496, p=0.195\right)$. Shade tree pruning thus did not affect overall diversity within the plot.

\section{Discussion}

One interpretation of these data suggest that $C$. senex textor nest high in shade trees (and more on branches) than $A$. instabilis, and thus are greatly influenced by pruning. Immediately after pruning, 

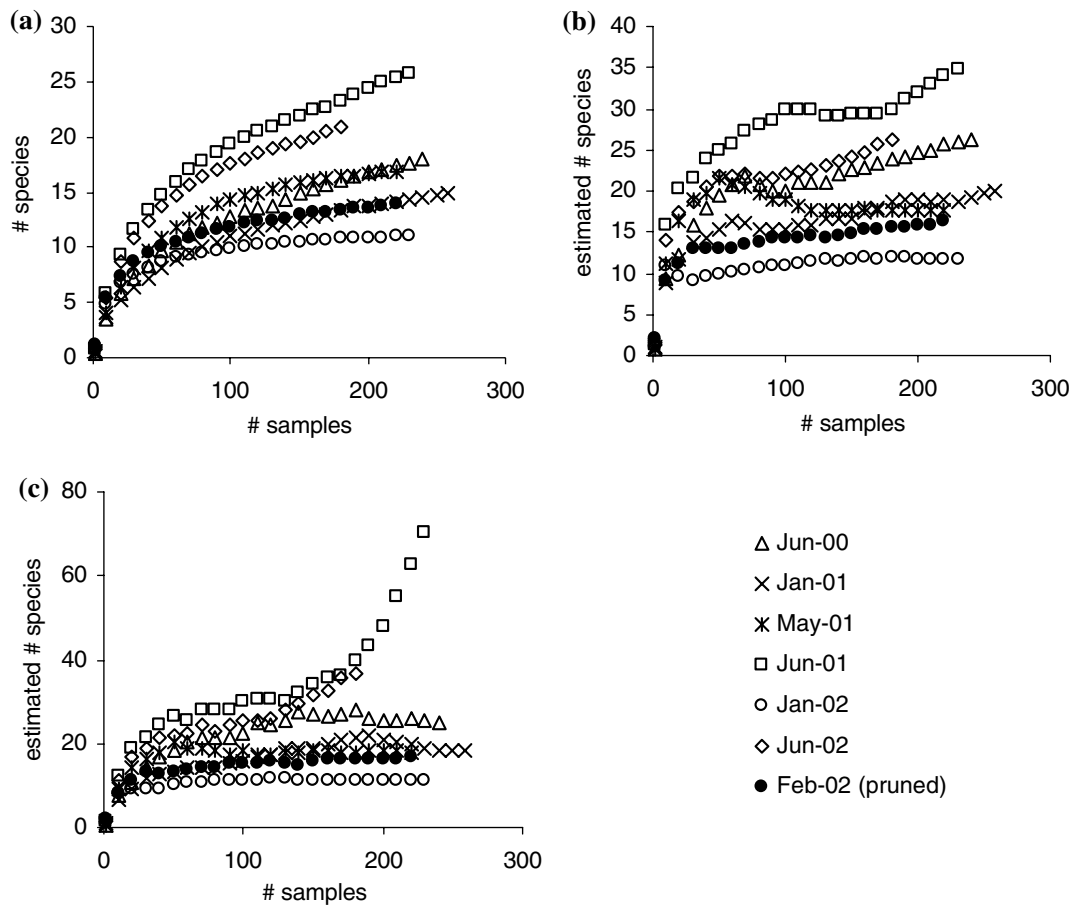

Figure 3. Species accumulation curves for arboreal ants in one $25 \times 50 \mathrm{~m}$ coffee plot in Chiapas, Mexico during sampling dates where shade trees were not pruned and at one date (February 2002) where shade trees were pruned 1 week before sampling. Accumulation curves for samples (number of plants and shade trees at each sampling date) for (a) observed data, (b) Incidence-based Coverage Estimator, and (c) Chao2 were generated with EstimateS.

several $C$. senex textor nests were observed on felled branches and many ants were observed scurrying rapidly up shade tree trunks carrying pupae and larvae back to the canopy, presumably to rebuild nests. During most sampling times, $C$. senex textor were not as common on coffee plants in the plot, nor were these ants foraging much on shade tree trunks, where tuna baits were placed. However, once shade tree branches were pruned, $C$. senex textor were ubiquitous in the plot. It thus appears that $C$. senex textor ants, in general, are always present but restrict their foraging largely to the shade tree canopy except following pruning which temporarily increases their presence on coffee plants.

In contrast, $A$. instabilis nests are generally located lower in the shade trees (normally between large branches or in the crotch of the tree), even in coffee plants (pers. obs. 2002). Azteca instabilis ants are more common throughout the plot and more often found on coffee plants. Because farm workers also apply lime to trees before climbing them to prune, $A$. instabilis ants were temporarily restricted. Data were not collected during the interval between 1 week and 6 months after pruning in order to determine exactly how long the temporary changes in ant abundance and distribution may be. Nevertheless, although there are not long-term changes to the ant community following pruning, the temporary effects of shade tree pruning (and lime application), may have important implications for other coffee management practices such as pest control.

Controlling the types and quantities of ants on coffee plants may be one strategy for effective biological control in coffee agroforestry systems. Azteca instabilis are potentially important biological control agents in coffee agroforestry systems (Vandermeer et al. 2002). Additionally, although $A$. instabilis may be a more effective predator, $C$. senex textor can also negatively influence pests (S. Philpott, unpublished data). During most sampling periods, A. instabilis was much more frequently encountered on coffee plants, thus may have positive effects on coffee plants via their negative interactions with coffee pests (such as the coffee berry borer). When trees are pruned, however, $C$. senex textor was much more abundant but there 
were also significantly fewer plants without ants. However, C. senex textor, after pruning, was not necessarily foraging for prey in either coffee plants or in shade trees, but rather relocating nests. Thus after pruning, in general, there were more ants on plants, but at other times, there were more efficient ant predators on particular plants. These changes in ant abundance due to pruning, although difficult to assess, may be important to consider when designing pest management strategies.

\section{Acknowledgements}

I thank J.A. García Ballinas, G. López, J. Maldonado, B.E. Chilel, J.C. Méndez López, A. Méndez Mendizábal, A. Hammond, F.B. Camposeco Silvestre, J.L. Cabrera Santos, L.H.L. Ramírez, and A. González for field help. The Peters family allowed us to work on their farms. G. Ibarra Núñez at El Colegio de la Frontera Sur in Tapachula provided logistical support. This research was supported by NSF Grant \#DEB9981526, the University of Michigan, and an NSF Graduate Research Fellowship to S. Philpott.

\section{References}

Armbrecht I. and Perfecto I. 2003. Litter-dwelling ant species richness and predation potential within a forest fragment and neighboring coffee plantations of contrasting habitat quality in Mexico. Agric. Ecosyst. Environ. 97: 107-115.

Beer J., Muschler R., Kass D. and Somarriba E. 1997. Shade management in coffee and cacao plantations. Agroforest. Syst. 38: 139-164.

Colwell R.K. and Coddington J.A. 1994. Estimating terrestrial biodiversity through extrapolation. Philos. Trans. R. Soc. Lond. Ser. B-Biol Sci. 345: 101-118.
Longino J.T., Coddington J. and Colwell R.K. 2002. The ant fauna of a tropical rain forest: estimating species richness three different ways. Ecology 83: 689-702.

Moguel P. and Toledo V.M. 1999. Biodiversity conservation in traditional coffee systems of Mexico. Conserv. Biol. 13: 1121.

Peeters L.Y.K., Soto-Pinto L., Perales H., Montoya G. and Ishiki M. 2003. Coffee production, timber, and firewood in traditional and Inga-shaded plantations in Southern Mexico. Agric. Ecosyst. Environ. 95: 481-493.

Perfecto I., Rice R.A., Greenberg R. and VanderVoort M.E. 1996. Shade coffee: a disappearing refuge for biodiversity. Bioscience 46: 598-608.

Perfecto I. and Snelling R. 1995. Biodiversity and the transformation of a tropical agroecosystem - ants in coffee plantations. Ecol. Appl. 5: 1084-1097.

Perfecto I., Vandermeer J., Hanson P. and Cartin V. 1997. Arthropod biodiversity loss and the transformation of a tropical agro-ecosystem. Biodiv. Conserv. 6: 935-945.

Romero-Alvarado Y., Soto-Pinto L., García-Barrios L. and Barrera-Gaytá n J.F. 2002. Coffee yields and soil nutrients under the shades of Inga sp. vs. multiple species in Chiapas, Mexico. Agroforest. Syst. 54: 215-224.

Soto-Pinto L., Perfecto I., Castillo-Hernández J. and CaballeroNieto J. 2000. Shade effect on coffee production at the northern Tzeltal zone of the state of Chiapas, Mexico. Agric. Ecosyst. Environ. 80: 61-69.

Staver C., Guharay F., Monterroso D. and Muschler R.G. 2001. Designing pest-suppressive multistrata perennial crop systems: shade-grown coffee in Central America. Agroforest. Syst. 53: 151-170.

Vandermeer J., Perfecto I., Nunez G.I., Philpott S. and Ballinas A.G. 2002. Ants (Azteca sp.) as potential biological control agents in shade coffee production in Chiapas, Mexico. Agroforest. Syst. 56: 271-276.

Velez M., Bustillo A.E. and Posada F.J. 2001. Hormigas de la zona central cafetera y perspectivas de su uso en el control de Hypothenemus hampei (Ferrari) (Coleoptera: Scolytidae). In: Velez M., Bustillo A.E. and Posada F.J. (ed.), Resúmenes XXVIII Congreso. Sociedad Colombiana de Entomología, Pereira, Colombia 51.

Way M.J. and Khoo K.C. 1992. Role of ants in pest-management. Annu. Rev. Entomol. 37: 479-503. 